\title{
Education Without Boundaries: Faculty Training And Support
}

\begin{abstract}
This paper looks at two specific issues related to faculty success in the online classroom. The first, an effective faculty training program, is crucial in building a cadre of competent online faculty to meet the growing demands for web-based classes. However, the training programs offered vary significantly from on-the-job training to intensive immersion programs which take place before the first online teaching assignment. The second issue is ongoing support including administrative, academic, and technical support. While effective training is instrumental in getting the faculty member prepared for cyberspace, the support services available while teaching the online class are often responsible for how smoothly the course runs.
\end{abstract}

\section{INTRODUCTION}

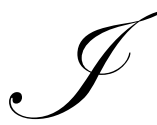

$n$ the early days of distance education, faculty had to be coaxed to teach off-campus classes often at corporate locations or rented space at an off-campus site. Today, while universities continue to increase their off-campus offerings, the newest and fastest-growing trend in distance education requires no additional physical overhead for the university because the teaching and learning take place in cyberspace with the use of web-based media. Online education is relatively new only beginning in earnest in the mid 90s as the Internet proliferated and the average potential student had access to a personal computer.

By 1997, the trends in distance learning were so undeniable that famed management guru, Peter Drucker, was quoted as saying,

Universities won't survive. The future is outside the traditional classroom. Distance learning is coming on fast." (Gubernick \& Ebeling, 1997)

In a 2001 study, Shea and Boser reported that $70 \%$ of U.S. universities already had online courses and predicted that this number would grow to $90 \%$ by 2005 .

This article examines two faculty issues related to success in cyberspace: faculty training and support. The first, faculty training, is a process which should occur prior to someone teaching his or her first cyberclass. It is separated out from other types of support because it is such a huge subject on its own. Research and personal observation have led the authors to believe that faculty performance in the online environment is the most important determinant of student success. Even more so than in the traditional classroom, faculty who are comfortable in their role of facilitator and who can take the lead in modeling effective online interaction will create the collaborative learning environment correlated to effective online education.

\section{THE NEED FOR FACULTY TRAINING}

The authors are senior faculty members at Nova Southeastern University which has long been known for its distance education programs. Each spent over a decade administering either undergraduate or graduate business programs which were offered in a variety of locations. One pioneered the first online business degree at NSU and both were among the first NSU business faculty to design and teach online courses. Since then, they have taught 
dozens of classes, written several articles, and attended many conference sessions on the efficacy of online pedagogy. They have participated in learner outcome studies and are firm believers that online students have the potential to accomplish the same exit outcomes as their traditional onground counterparts. Yet, the authors have witnessed great variation in the both the skill and comfort level of other faculty, both at NSU and other institutions with which they have contacts. Finally, they offer the findings of an earlier study which suggested:

It is apparent...that the online instructor is the single most important person in making the student's xperience a positive or a negative one...partial answers rely on training instructors well before sending them to cyberspace and ensuring that they are dedicated to carefully articulated expectations like accessibility to students, 24 hour feedback, and weekly grading. (Gibson, Tesone, Hodgetts, \& Blackwell, 2001, 376.

It is not that the element of teaching expertise is only important in online classes. During the authors' combined 45 years of college level teaching experience, it has been observed that students will forgive just about anything but poor teaching. However, the online class experience requires new skills and methods. It takes the traditional professor out of his or her role of "sage on the stage" and casts that person as a facilitator who provides information and guidance to students who are far more participative and more in charge of the learning that take place. Learning these new teaching skills is only one part of the challenge. At the same time, the online neophyte must learn the technology and the protocols of the particular program. Equally challenging, they must put their own class materials into formats which can be communicated over the Internet.

In a study which collected data from 81 business professors who taught online classes at 61 AACSB accredited, U. S. business schools, a majority of respondents (63\%) reported that they had taught themselves how to transist to the online environment without any type of formal training program. (Perreault, Waldman, Alexander \& Zhao, 2002). Juxtapose this finding on the fact that many business faculty have never been taught to teach in the first place (Gallant, 2000) and the continuing pressure on business faculty to put their energy into researching as opposed to teaching (Hitch \& Hirsch, 2001), it is no wonder that the authors perceive a system-wide lack of qualified online instructors in need of training programs. So, how do interested faculty learn what it takes to go to cyberspace? This question leads to a discussion of a variety of training models currently in use.

\section{TRAINING MODELS}

The variety of faculty training models can be divided into formal or informal, voluntary or required. The more in-depth models, which the authors personally recommend, cover both the pedagogical and technical aspects of online training. They are both formal and, in most cases, required before an instructor teaches his or her first online course.

Yet, as witnessed by the study quoted above, a large number of online faculty either have no access to such formal training or opt out of these opportunities. The authors feel this is an unwise decision and agree with Prendergast (2000) who stated:

Not many people undertaking mountaineering for the first time would attempt to climb Everest on the first day. Yet many educators acquire some conferencing software and then try and design and run some kind of pilot online course. When their experiment fails, they rarely blame themselves, often stating that the medium is not very suitable for learning. (294)

Faculty who do not have access to formal training or who opt out of those which are voluntary still have informal methods of learning online teaching skills. Fortunately for this group, the availability of printed and Internet materials has increased tremendously in the last decade. Books, tutorials, and conferences dedicated to teaching an online course are relatively easy to find so no instructor need choose to start from zero when designing his or her first online course. (Gallant 2000)

For those who can avail themselves of more formal methods, a variety of training programs exist including coaching, workshops, and immersion training. 


\section{Coaching or Mentoring}

As mentioned earlier, one of the authors was director of undergraduate business programs at Nova Southeastern University (NSU) when the first online business program was launched. The Bachelors of Professional Management (BPM) is a 66 credit completion program originated in the late 70s for students who typically already have earned their associate's degree in an unrelated field, but who now want to move into management or supervision. An 18 month development timeline was set in the mid 90 s to bring the first set of courses online. A group of 6 faculty members was chosen to each develop and teach a course. None of the course developers had any previous experience with online teaching, but they were able to get valuable advice from their computer science colleagues who already had many online offerings. The latter demonstrated their courses and set up workshops to start the process. A technical person was chosen from among the business school staff to teach the six pioneers how to develop web pages from which their courses would be taught.

These first courses were laboriously written in HTML code by the teachers themselves. Show and tell sessions were scheduled by the director to keep everyone on track. It was significant to the project that the director, herself, was one of the six faculty developing courses since she could arrange additional coaching and mentoring as required. The success of the original six courses subsequently led to a second team of faculty being recruited and mentored by the first group. It is important to note that incentives such as development pay and the assurance that each instructor would have right of first refusal on future offerings of "their course" made faculty recruitment easier. Still this was a "learn by the seat of your pants" approach which was only achieved by the determination of the people involved and the ability of the school to start this program on a small scale. (Gibson \& Herrera, 1999)

\section{Workshops}

Many schools offer short workshops to help instructors transist to the online environment. NSU, for example, offers continual WebCT training for instructors as WebCT has become the school wide platform for online programs. These workshops are short (2-4 hours), progressive (basic to advanced) and completely voluntary.

An example of a required short workshop can be found at Troy State University's Ft. Benning, Georgia campus where online faculty must participate in a "quick start" program consisting of a 4 hour class about online course development. This start-up class is frequently offered so that new faculty can continuously be added to the ready list of online faculty. (Rinear, 2003)

Other schools have begun their online training programs with short workshops and then quickly enhanced their development efforts. One example is UMass - Lowell which started their online faculty development effort with a required 9 hour, face-to-face workshop. This quickly led to a comprehensive program including a four week online workshop where faculty act as both students and instructors. (Moloney \& Tello, 2003)

\section{Immersion Training}

Immersion training requires the prospective online faculty members to assume the role of a student in an online training course. By doing this, the faculty receive instruction while experiencing the learning platform, online pedagogy, and participation requirements from the perspective of a student. The content covers not only how to use the technology, but how to teach in an online environment, and what common elements are required in each course. The latter may include a required number of days per week which students must be online as well as a weekly requirement for faculty to provide meaningful, individual feedback.

The University of Phoenix is a leader in today's distance education market. Their website states that they currently have over 200,000 students and at least 50,000 of these students are attending the Online College. Brian Mueller, Vice President and Chief Operating Office of University of Phoenix Online explained in a 2002 article that much of their success is at least partially due to the 10-12 week intensive training program that all online faculty have to go through. (Roach, 2002) This training begins with each new faculty member (regardless of how long they have been teaching online) taking 5 or 6 week training course comparable to the 5 or 6 week courses he or she will 
be teaching once trained. The subject matter, however, consists of teaching candidates the platform, in this case Microsoft Outlook Express, as well as the pedagogy and philosophy required for all UoP classes. Candidates take part in weekly learning teams (which are a centerpiece of all UoP classes) and find out first hand how learning teams operate in cyberspace. They are expected to do readings and hand in assignments at much the same pace as the students. When this course is finished successfully, the candidate is assigned to teach a course with a mentor watching everything he or she does. This mentor does pre-course work with the candidate and approves his or her syllabus, lecture notes, etc. During the course, the mentor assesses the faculty member's communication skills, content knowledge, and adherence to required procedures. Only after passing ones mentorship is the prospective online faculty member offered his or her first class.

The University of Maryland is another example of a large scale program which requires immersion training for their University College online courses. Prospective faculty join a five week online class where they first assume the role of student and then later take turns assuming the role of the online instructor. Topics include creating web pages, crafting meaningful online assignments, and providing student feedback. (Wolf, 2003)

A third example of an immersion program is offered by Baker College in Flint, Michigan. Offering more than 200 online classes each term, Baker College also uses a large cadre of online faculty and strives to ensure that they adhere to a coherent online strategy by teaching them, among other things, the Baker Dozen guidelines governing all online classes. The authors have been through this training program and know from experience that it consists of three phases. First, the prospective faculty take a class where they assume the role of student and learn everything from the Blackboard platform which is used to how to ensure participation from each individual student. Baker's policy of sharing curriculum among faculty who teach the same course assures content help for the new hire. Next, the faculty trainee shadows a live class taught by a senior online faculty member. Only after completing both phases is the trainee assigned to his or her own class with a mentor as a shadow in the class. The role of the mentor is to provide advice and support during the newcomer's first class and to ensure that the Baker principles and requirements are followed. Thus students can expect a great deal of consistency from one class to another.

Regardless of the training mode, the authors agree with a recommendation made in the Journal of Instruction Delivery Systems:

So, regardless of the proposed intrinsic benefits of training, the extrinsic incentives must not be left out. People need certain levels of immediate rewards for undertaking training that has little immediate impact on their teaching style and career. These extrinsic motivations include monetary, emotional, and physical efforts such as stipends, social opportunities, and food during training. (Star, 2001, 9)

The school in question, South Dakota State University, offered faculty the opportunity to take summer training courses which carry a stipend of $\$ 150$ a day. (Star, 2001)

\section{ONGOING SUPPORT}

In addition to the need for continuing training opportunities, ongoing university support is needed in administrative, technical, and academic areas.

\section{Administrative Support}

Administrative support can be divided into three categories or levels: university, college, and department. (Dahl, 2003) At the university level, policy decisions related to online programs must be instituted. Approval must be given to initiate online programs and the appropriate budgetary allocations must be made. Additionally, technical support and faculty training programs may either be centered at the university or college level. Often, the decision is made at the university level as to which online platform to support. For example, at NSU, the university has mandated that all online programs be run on WebCT. 
At the college level, faculty committees often are involved in designing the online programs and administrator/faculty teams develop requirements, guidelines, and protocols. These recommendations usually go to the Dean or his or her designees for review and approval before online classes can start. It is important at this level that the Dean and the rest of the academic leadership support the online philosophy and are willing to generate enthusiasm among the faculty and staff for these programs if they are to succeed.

Administrative leadership is also crucial in influencing instructors and other potential participants into committing their time and efforts developing and implementing a web-based curriculum. In this regard, at one institution, senior administration has waived out-of-state tuition for foreign students taking web courses prior to their coming to campus. (McAllister, Rivera \& Hallam, 2001, para. 7)

At the department level, appropriate accommodations must be made for online faculty who need onground course reductions, online versus office hours, development time, and incentives to get involved in the online environment.

\section{Technical Support}

In a study by Perreault et. al. (2002), a survey of 81 business professors at 61 different schools showed, among other things, that $80 \%$ of the respondents were troubled by technical glitches of one type of another. Even small problems such as a server being temporarily down were frustrating to the faculty. Fifty percent of the respondents said that there was not enough technical support by the institution to adequately support the course.

Well-developed online programs provide technical assistance for both faculty and students in an easy-toaccess mode. NSU, for example, not only has a 7 day per week help desk, but it has a "live help" feature where the student or faculty member can click on "live help" and a technical person will respond in real time to discuss and solve the problem. The University of Phoenix has a dedicated faculty help line which is staffed 24/7 as well as a student help center. Each provide expert technical assistance on a wide variety of problems and guarantee that the faculty or students don't get bogged down in technical problems.

\section{Academic Support}

There are a wide variety of academic support services which should be provided to the online student in much the same way as they are provided to the onground student although the format may change. These services include not only academic advising, but tutorial assistance and online library resources. The University of Phoenix has a full service writing lab where students can submit their papers and get a 48 hour turnaround with recommendations for improvement, critique of APA style, etc. Likewise the undergraduate online business program at NSU has a learning lab which provides writing assistance to its online students.

One of the most important support services desired by faculty is student access to online library resources. Programs without this service are implicitly encouraging students to do their research by Internet sources alone which often consist of other than published journal articles. The online programs with which the authors are familiar, NSU, University of Phoenix, Baker College, and Warner Southern College all have full text, online library services which are available free of charge to registered students.

\section{CONCLUSION}

Faculty training and support are critical for several reasons. First, without such training and support, it is unlikely that uninitiated faculty members are going to want to make the trip to cyberspace. It is simply too work and time intensive. Secondly, training and support of the type discussed above will go a long way in making the faculty member successful in the online environment and willing to teach future cyberclasses. Thirdly, training and support provide a strong indicator of the level of commitment the institution has to online programs. Finally, training and support programs guarantee a level of coherence and similarity among courses that will be comforting to students and helpful to administration in documenting learning outcomes. 
Teaching online classes is not for everyone. The learning curve is steep for the newcomer, but with the right amount of institutional support and availability of training, it is likely that more people will be willing to try teaching in this expanding environment.

\section{REFERENCES}

1. Gallant, G. (Winter 2000). Professional development for web-based teaching: Overcoming innocence and resistance. New Directions for Adult and continuing Education, 88: 69-78.

2. Gibson, J. W. \& J. M. Herrera (January 1999). How to go from classroom based to online delivery in eighteen months or less: A case study in online program development. T.H.E. Journal, 57-61.

3. Gibson, J., Tesone, D., Hodgetts, R. and C. Blackwell. The human dimension of online education: Cyberstudents speak out. IPCC Proceedings, 2001, 367-378.

4. Gubernick, L. \& Ebeling, A. (June 16, 1997). I got my degree through e-mail. Forbes: 44-92.

5. Hitch, L. \& Hirsch, D. (January 2001). Model training. The Journal of Academic Librarianship, 27:1: 1519.

6. McAlister, M., Rivera, J., and Hallam, S. (2001). Twelve important questions to answer before you offer a web-based curriculum. Online Journal of Distance Learning Administration, IV: 2. Retrieved August 18, 2004 from http://www.westga.edu/ distance/ojdla/summer42/mcalister42.html

7. Moloney, J. \& Tello, S. (February 1, 2003) Principles for building success in online education (electronic version) retrieved August 13, 2004 from http://www.syllabus.com/print.asp?ID=7252

8. Perrault, H., Waldman, L, Alexander, .and J. Zhao. (July/August 2002). Overcoming barriers to successful diversity of distance-learning courses. Journal of Education for Business 77:6, 313-318.

9. Prendergast, G, (2000) Creating effective online collaborative educators in Asensio, A., Foster, J. Hodgson, $\mathrm{V}$ and McConnell D (eds) Networked Learning: Innovative Approaches to Lifelong Learning and Higher Education Through the Internet. Lancaster-Sheffield: Lancaster University and University of Sheffield.

10. Rinear, K. (January 15, 2003). Quick-start training puts instructors online fast. Distance Education Report 7:2.

11. Roach, R. (February 28, 2002) Tested practices buoy University of Phoenix Online. Black Issues in Higher Education 19:1, 54-55.

12. Shea, R. \& Boser, U. (October 15, 2001). Special report: E-learning guide. U.S. News \& World Report, 44. 